\title{
Review
}

\section{Treatment of irritable bowel syndrome: a review of randomised controlled trials}

\begin{abstract}
Summary
Irritable bowel syndrome (IBS) is a common chronic disorder that is associated with significant disability and health care costs. The purpose of this paper is to review and assess published randomised controlled trials examining the clinical effectiveness of interventions for IBS for 19871998. A literature search was conducted to identify randomised controlled trials of IBS treatments: 45 studies were identified that described randomised controlled trials and of these, six fulfilled all three criteria used to assess the quality of randomised controlled trials, as described by Jadad and colleagues. ${ }^{1}$ These criteria are: adequate description of randomisation, double blinding, and description of withdrawals and dropouts. It is concluded that there are few studies which offer convincing evidence of effectiveness in treating the IBS symptom complex. This review strongly suggests that future work should include well designed trials that: describe the randomisation method; use internationally approved diagnostic criteria; and are double blinded and placebo controlled. Clear well defined outcome measures are necessary. Inclusion of quality of life measures allows comparison between trials in different therapeutic areas. Conducting such studies will help to overcome some of the difficulties identified in this review.
\end{abstract}

\section{Introduction}

IBS is the most common functional bowel disorder and affects about $20 \%$ of all people at any one time. ${ }^{23}$ It is a condition characterised by abdominal pain associated with defecation, or a change in bowel habit and with features of disordered defecation and distension in the absence of any demonstrable abnormality. ${ }^{2}$ Three subgroups exist: one third of patients suffer constipation, one third suffer diarrhoea, and the rest suffer alternating constipation and diarrhoea. ${ }^{34}$ While patients with symptoms of IBS represent $20-50 \%$ of referrals to gastroenterologists, there are many who do not seek medical attention. ${ }^{5}$

The burden of illness associated with IBS is considerable. One recent study in the $\mathrm{UK}^{6}$ found IBS sufferers to report substantially lower quality of life scores, as measured by the SF36, than the control group. Sufferers also used health service resources to a greater extent and missed more days off work than the control group.

A number of pharmaceutical companies have new drugs in development to treat IBS and there is interest in the use of psychotherapy, either alone or in conjunction with other therapy. Before these therapies are adopted it is important to assess the evidence on the effectiveness of what is already available. It is highly likely that in the very near future a crop of new efficacy studies will be published.

This paper therefore reviews the quality and direction of current evidence.

\section{Methods}

LITERATURE SEARCH

To identify the studies used in this review, the following databases were searched: Cochrane Library, Database of Abstracts of Reviews of Effectiveness (DARE), Medline, and Embase. The key words "colonic diseases", "functional", and "clinical trials" were used. General reviews, meta-analyses, and references from published randomised controlled trials (RCTs) were also used. Trials published between 1987 and 1998 in English, French, German, Italian, and Spanish were included.

\section{INCLUSION CRITERIA}

In order to be included in this review, a study had to have been published in a peer reviewed journal and to be judged by the authors of this review to be truly randomised. RCTs dealing with bulking agents, anticholinergics/ antispasmodics, antidiarrhoeals, prokinetic drugs, antidepressants including psychotropic drugs, serotonergic antagonist drugs, combinations of drugs, as well as recent and miscellaneous drugs were included. Trials comparing different treatments without placebo control groups were also included. High fibre diet or a fibre supplementation taken in all randomised groups was also included.

EXCLUSION CRITERIA

Trials published as abstracts or letters, or not clearly randomised were excluded. RCTs which analysed drugs with only a pharmacological effect on motility were also excluded.

ASSESSMENT OF RCTS

In the RCTs identified, the following points were assessed:

- sample size

- number of dropouts

- extent to which blinding was used

- intervention

- outcome measures such as global assessment of symptoms by the patient or physician, abdominal pain, constipation, diarrhoea, or abdominal distension.

\section{Results}

A total of 227 studies were identified between 1987 and 1998. There was some duplication of the studies identified from the various databases. Of these 227 studies, 93 described trials. Only 45 trials were used in this review as the remaining 48 were either not randomised or studies of gut motility. The interventions described included: bulking agents, anticholinergics/antispamodics, antidiarrhoeals, serotonergic drugs, antidepressants/psychotropic drugs, prokinetic drugs, as well as recent and miscellaneous drugs. These 45 studies are outlined in table 1.

The quality of these 45 trials was assessed according to the simple criteria laid down by Jadad and colleagues ${ }^{1}$ : whether the method of randomisation was described; whether the study was double blinded; and whether a description of withdrawals and dropouts from the study was included. It is possible that these studies used appropriate methods of randomisation but failed to describe them. Other more complicated critical appraisal checklists are available. ${ }^{52}$ However, it was felt that very few

Abbreviations used in this paper: IBS, irritable bowel syndrome; RCT, randomised controlled trial 


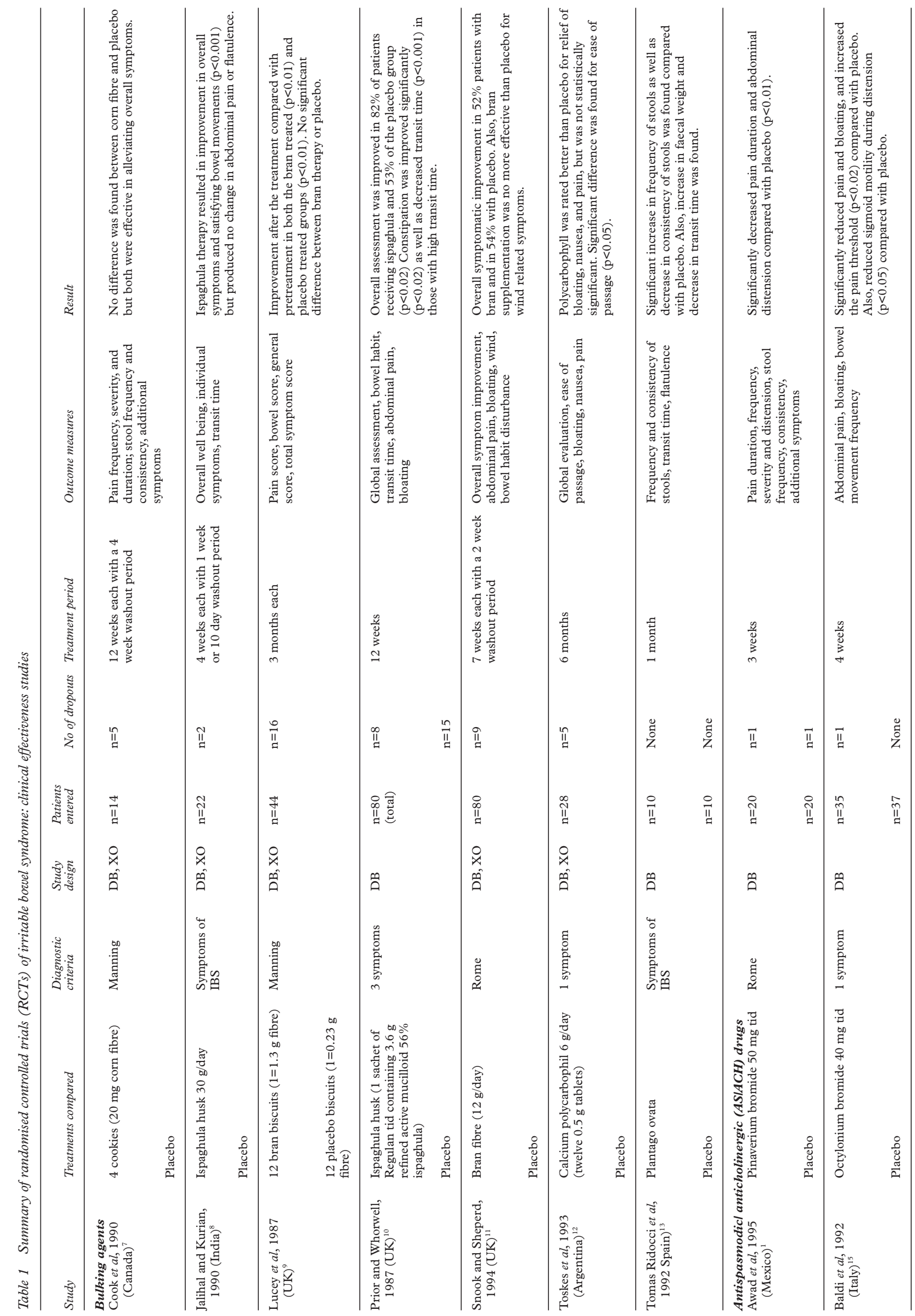




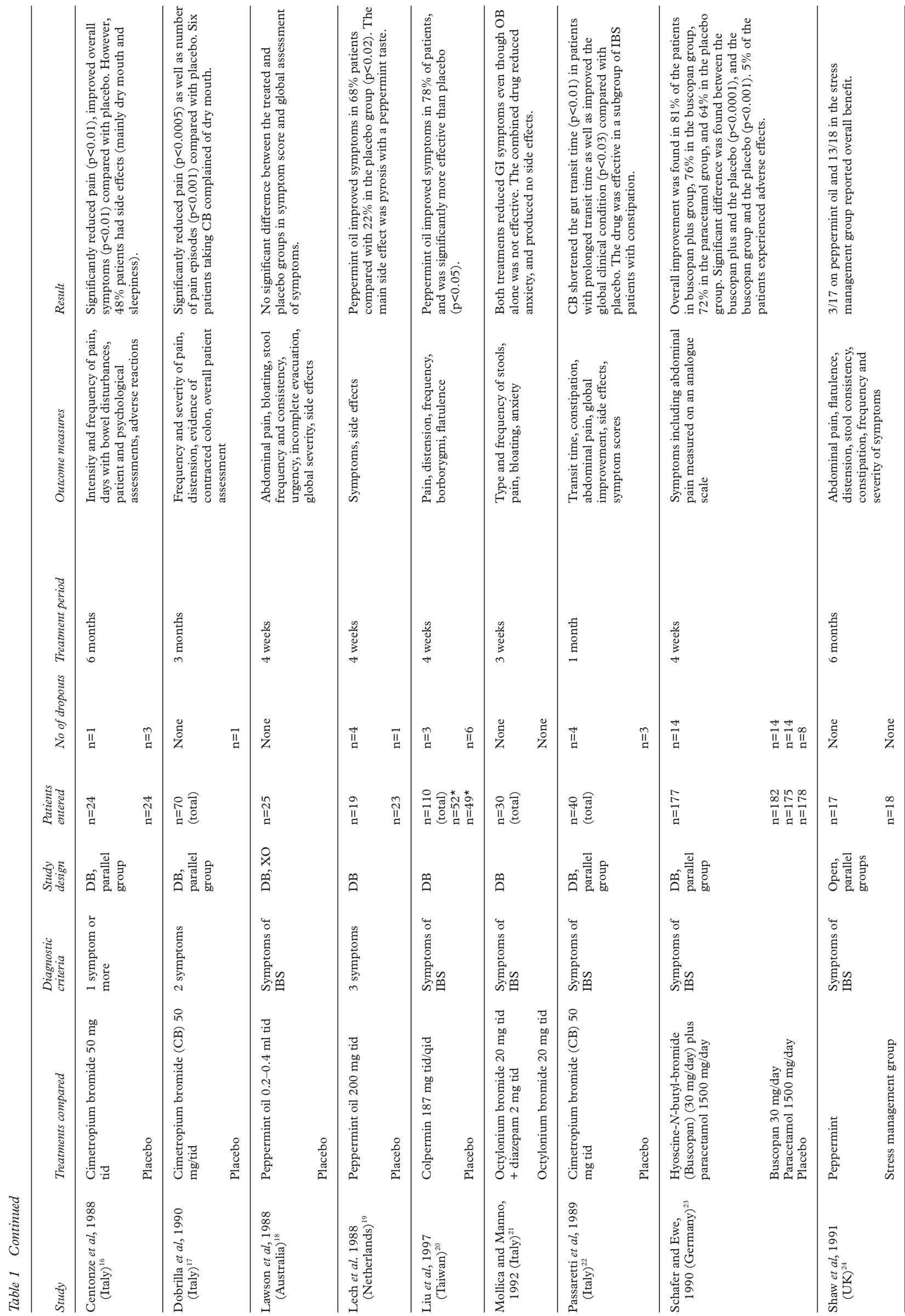



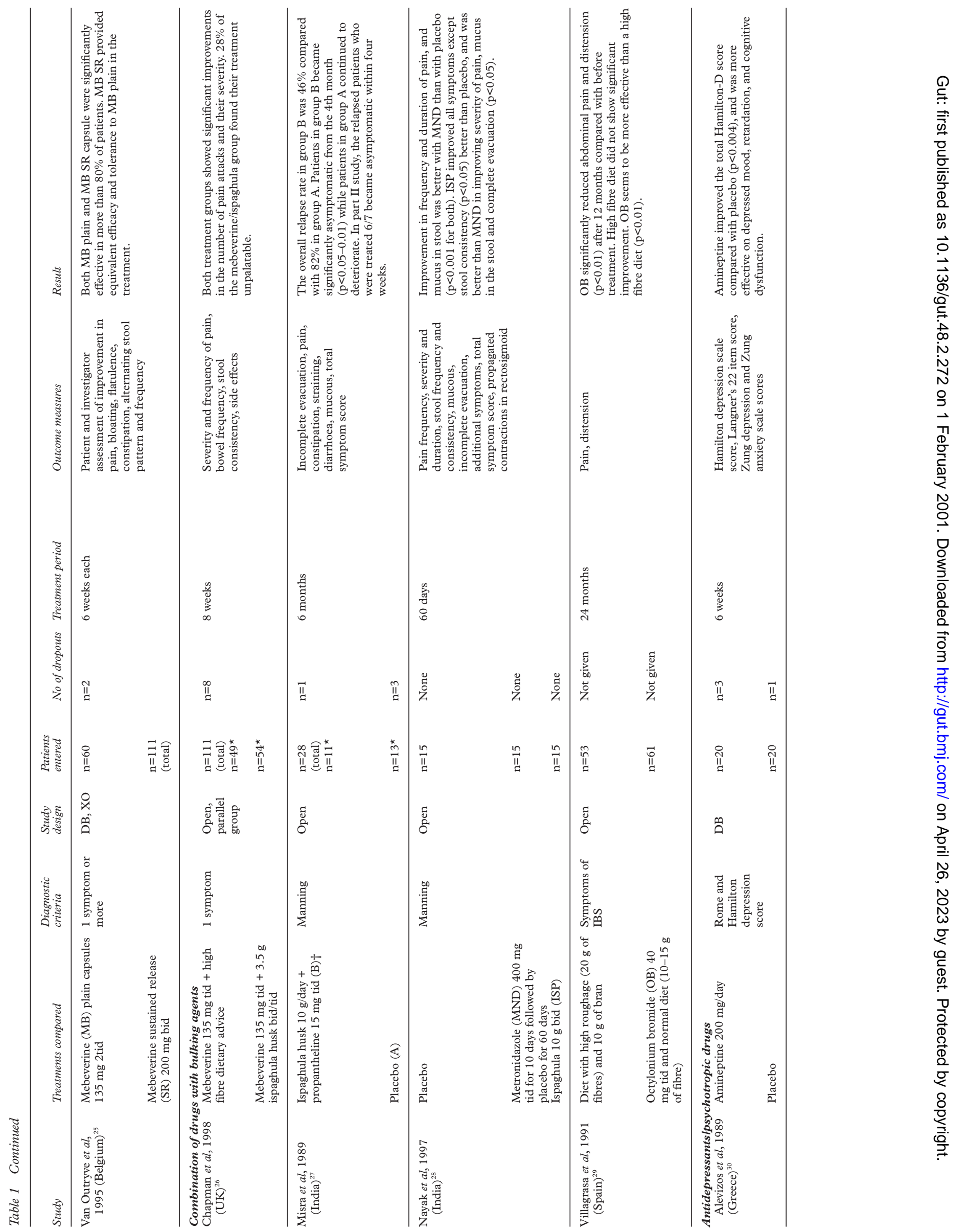

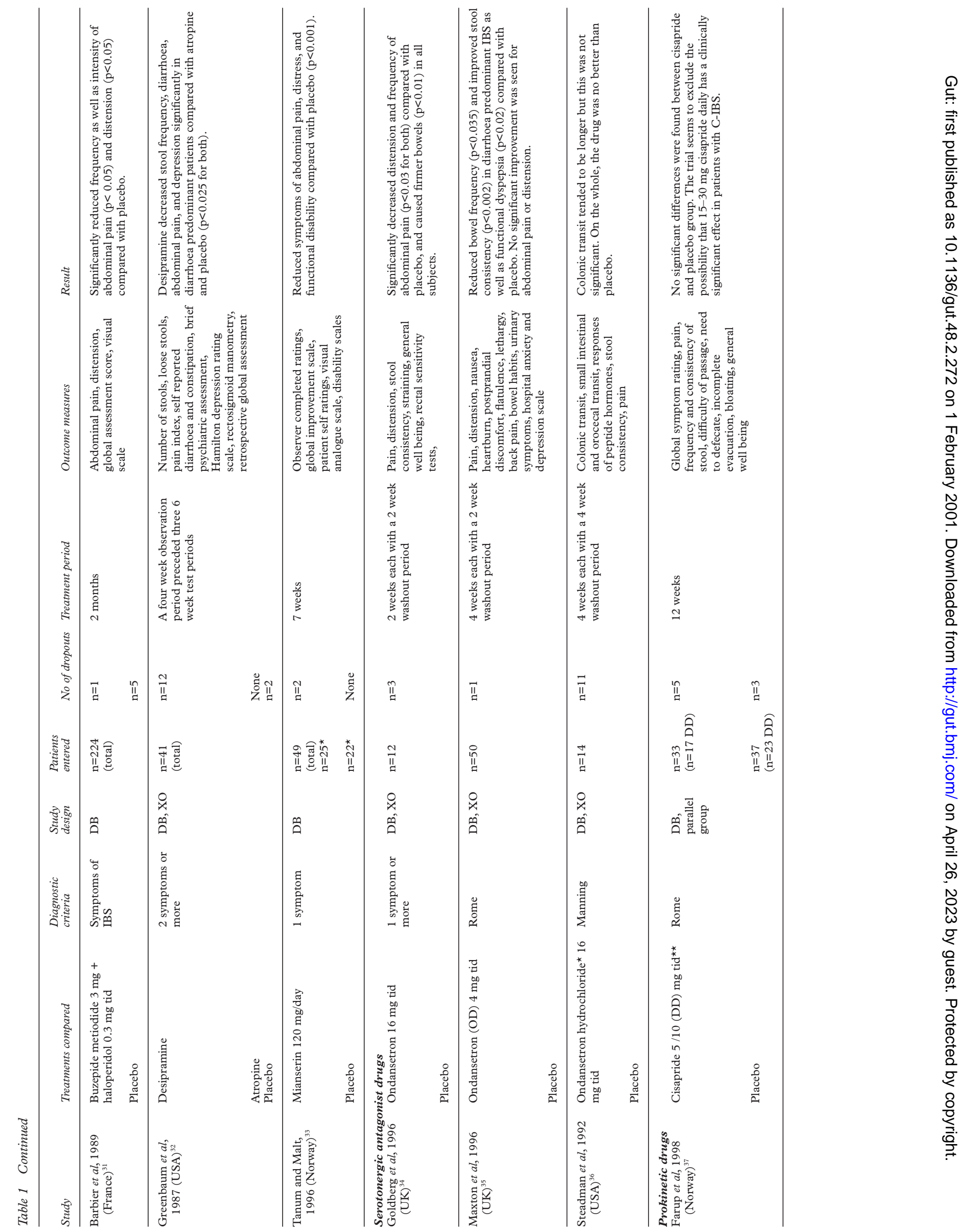


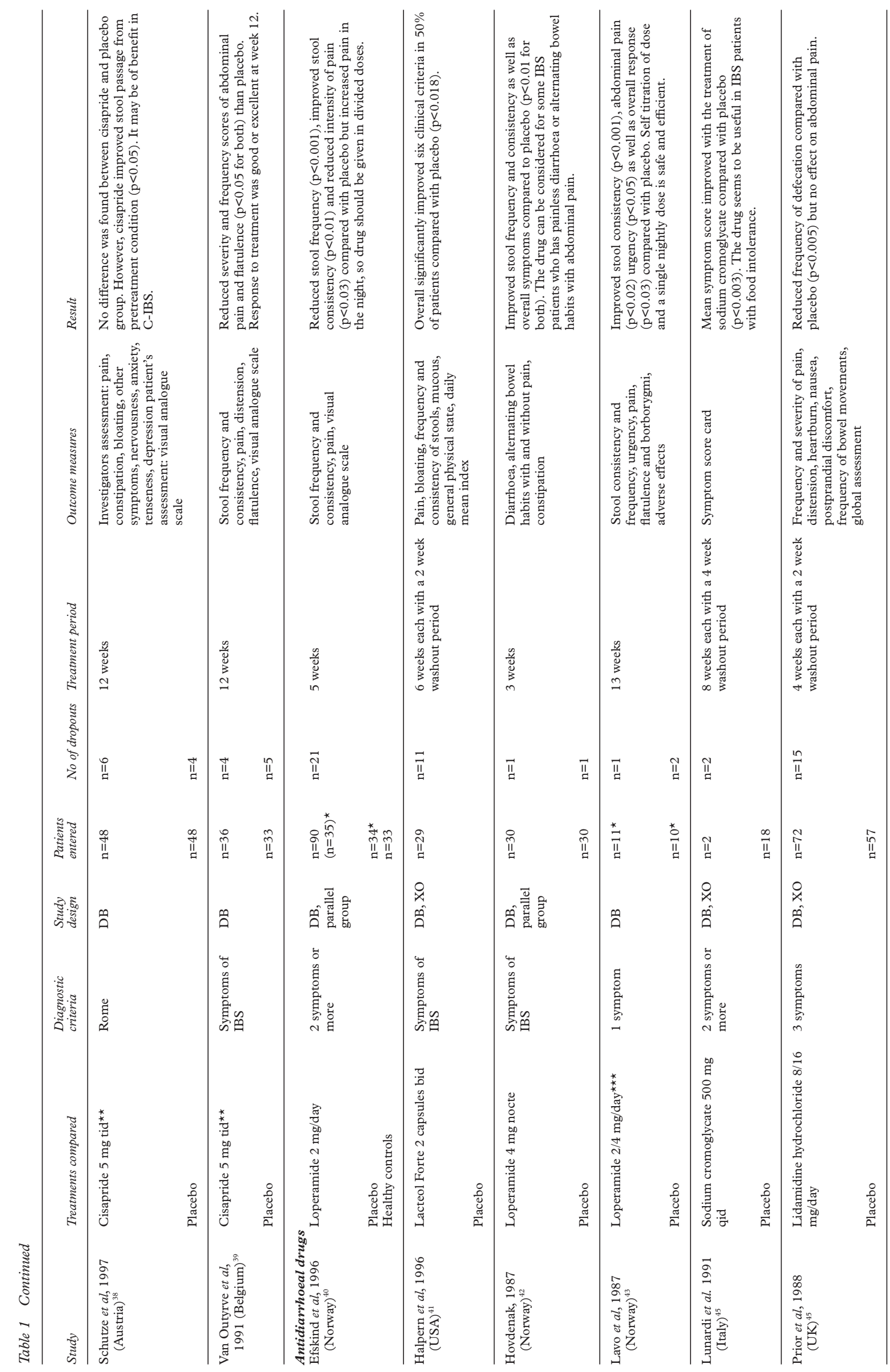

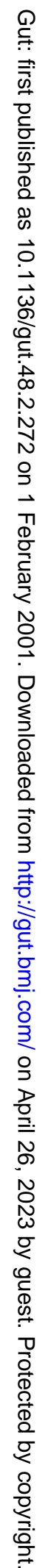



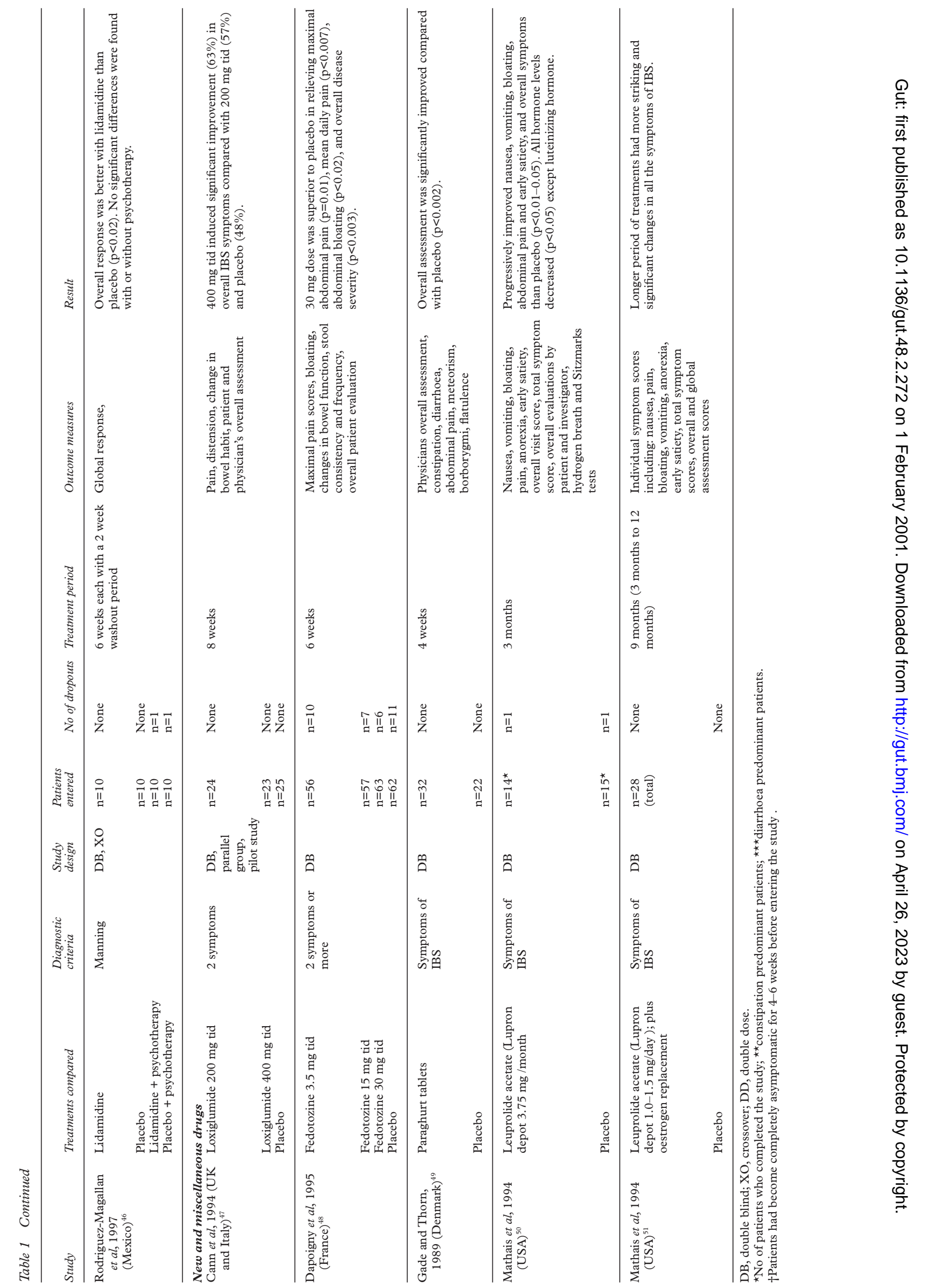
Table 2 Quality assessment of irritable bowel syndrome randomised controlled trials

\begin{tabular}{|c|c|c|c|}
\hline Study & $\begin{array}{l}\text { Randomisation } \\
\text { method }\end{array}$ & $\begin{array}{l}\text { Double } \\
\text { blind }\end{array}$ & $\begin{array}{l}\text { Description of } \\
\text { withdrawals } \\
\text { and dropouts }\end{array}$ \\
\hline Alevizos et al, $1989^{30}$ & Random numbers & Yes & Yes \\
\hline Awad et al, $1995^{14}$ & No method described & Yes & Yes \\
\hline Baldi et al, $1992^{15}$ & No method described & Yes & Yes \\
\hline Barbier et al, $1989^{31}$ & Drawing lots & Yes & Yes \\
\hline Cann et al, $1994^{47}$ & No method described & Yes & Yes \\
\hline Centonze et al, $1988^{16}$ & No method described & Yes & Yes \\
\hline Chapman et al, $1990^{26}$ & No method described & No & Yes \\
\hline Cook et al, $1990^{7}$ & No method described & Yes & Yes \\
\hline Dapoigny et al, $1995^{48}$ & No method described & Yes & Yes \\
\hline Dobrilla et al, $1990^{17}$ & Consecutive outpatients & Yes & Yes \\
\hline Efskind et al, $1996^{40}$ & No method described & Yes & Yes \\
\hline Farup et al, $1998^{37}$ & No method described & Yes & Yes \\
\hline Gade and Thorn, $1989^{49}$ & No method described & Yes & Yes \\
\hline Greenbaum et al, $1987^{32}$ & No method described & Yes & Yes \\
\hline Goldberg et al, $1996^{34}$ & No method described & Yes & Yes \\
\hline Halpern et al, $1996^{41}$ & No method described & Yes & Yes \\
\hline Hovdenak, $1987^{42}$ & No method described & Yes & Yes \\
\hline Jalihal and Kurian, $1990^{8}$ & No method described & Yes & Yes \\
\hline Lavo et al, $1987^{43}$ & No method described & Yes & Yes \\
\hline Lawson et al, $1988^{18}$ & No method described & Yes & Yes \\
\hline Lech et al, $1988^{19}$ & No method described & Yes & Yes \\
\hline Liu et al, $1997^{20}$ & No method described & Yes & Yes \\
\hline Lucey et al, $1987^{9}$ & No method described & Yes & Yes \\
\hline Lunardi et al, $1991^{44}$ & No method described & Yes & Yes \\
\hline Mathias et al, $1994 \mathrm{a}^{50}$ & No method described & Yes & Yes \\
\hline Mathias et al, $1994 \mathrm{~b}^{51}$ & No method described & Yes & Yes \\
\hline Maxton et al, $1996^{35}$ & No method described & Yes & Yes \\
\hline Misra et al, $1989^{27}$ & Consecutive patients & No & Yes \\
\hline Mollica and Mano, $1992^{21}$ & No method described & Yes & Yes \\
\hline Nayak et al, $1997^{28}$ & No method described & Yes & Yes \\
\hline Passaretti et al, $1989^{22}$ & Consecutive outpatients & Yes & Yes \\
\hline Prior and Whorwell, $1987^{10}$ & Consecutive patients & Yes & Yes \\
\hline Prior et al, $1988^{45}$ & No method described & Yes & Yes \\
\hline \multicolumn{4}{|l|}{ Rodriguez-Magallan et al, } \\
\hline $1997^{46}$ & No method described & Yes & Yes \\
\hline Schafer and Ewe, $1990^{23}$ & No method described & Yes & Yes \\
\hline Shaw et al, $1991^{24}$ & No method described & No & Yes \\
\hline Schutze et al, $1997^{38}$ & No method described & Yes & Yes \\
\hline Snook and Sheperd, $1994^{11}$ & Consecutive patients & Yes & Yes \\
\hline Steadman et al, $1992^{36}$ & No method described & Yes & Yes \\
\hline Tanum and Malt, $1996^{33}$ & No method described & Yes & Yes \\
\hline Tomas Ridocci et al, $1992^{13}$ & No method described & Yes & Yes \\
\hline Toskes et al, $1993^{12}$ & No method described & Yes & Yes \\
\hline Van Outyrve et al, $1991^{39}$ & No method described & Yes & Yes \\
\hline Van Outryve et al, $1995^{25}$ & No method described & Yes & Yes \\
\hline Villagrasa et al, $1991^{29}$ & No method described & No & No \\
\hline
\end{tabular}

trials would have been included in a more rigorous list of criteria. Table 2 summarises the characteristics of the 45 trials to which the Jadad criteria were applied.

When applying the criteria, only six of the RCTs identified provided adequate information, ${ }^{10} 1117223031$ highlighting the lack of well designed and well reported trials of IBS. Of the six studies meeting the criteria, two were of bulking agents, ${ }^{10}{ }^{11}$ two were of antispasmodic or anticholinergic drugs, ${ }^{17} 22$ and two were of antidepressant/ psychotropic drugs. ${ }^{30} 31$ The fact that only six studies met even such a relatively minimal set of criteria suggests that the quality of the current evidence is not good. Because so few studies met the criteria, further discussion has not been confined to them but has embraced all 45 studies listed in table 2 .

\section{BULKING AGENTS}

Seven double blind, placebo controlled trials of bulking agents are listed in table 1. The study carried out by Snook and Shepherd ${ }^{11}$ of 80 patients in a double blind, crossover trial not only found bran supplementation to be no more effective than placebo in improving individual symptoms of IBS but for wind related symptoms it was significantly less effective. Prior and Whorwell ${ }^{10}$ examined a total of 80 patients and found significant differences in bowel habit and transit time in those with constipation and in overall well being between the groups receiving ispaghula husk and placebo.
The appears to be some evidence that bulking agents may be effective in treating constipation associated with IBS although there is little reason to believe that they are effective for the entire IBS symptom complex.

ANTISPASMODICS/ANTICHOLINERGIC DRUGS

Twelve trials of antispasmodics (most of which were anticholinergics) were identified. Passaretti and colleagues ${ }^{22}$ carried out a study on 40 patients who were given cimetropium bromide ( $50 \mathrm{mg}$ three times daily) or placebo for one month and found that the antispasmodic significantly $(\mathrm{p}<0.01)$ shortened whole gut transit time in patients with prolonged transit time. It also improved the global clinical condition compared with placebo $(p=0.029)$. These findings were further supported by Dobrilla and colleagues ${ }^{17}$ in a three month study. In this study of 70 consecutive outpatients, cimetropium bromide (50 mg three times daily) was found to significantly reduce pain as well as the number of pain episodes compared with placebo at the end of three months $(\mathrm{p}<0.001)$. Moreover, $89 \%$ of patients treated with cimetropium considered themselves to be globally improved compared with $69 \%$ in the placebo group $(\mathrm{p}=0.039)$.

\section{ANTIDEPRESSANT/PSYCHOTROPIC DRUGS}

In general, antidepressants are used for patients with persistent painful symptoms with or without associated psychiatric morbidity. It has been suggested that the tricyclic antidepressants may have a beneficial effect in IBS mediated via a mechanism other than their antidepressant activity. ${ }^{53}$ Four trials of antidepressants were reported. Alevizos and colleagues ${ }^{30}$ described a study comparing the antidepressant amineptine $200 \mathrm{mg}$ /day with placebo for six weeks in 40 patients who satisfied the criteria for IBS and scored at least 15 in the 24 item Hamilton depression scale (HAM-D). The study found that amineptine produced significantly greater improvement for the total Hamilton score than patients who received placebo at the end of the trial period. Amineptine was more effective in treating depressed mood, retardation, and cognitive dysfunction. Barbier and colleagues ${ }^{31}$ studied the efficacy and safety of a combination of buzepide metiotide and haloperidol for two months in 224 patients. This combination resulted in improvement in frequency of symptoms and intensity of the most frequent symptoms, abdominal pain and distension, compared with placebo. Patients receiving the drug combination also reported greater global improvement than the placebo group.

\section{Discussion}

DIAGNOSTIC CRITERIA (ENTRY CRITERIA) USED IN TRIALS

A major consideration in the design of a treatment trial is characterisation of the entity to be studied as this will determine the nature of the patients who are enrolled. Unless physiological markers are found, the diagnosis of IBS is usually made on the basis of clinical history (the presence of abdominal pain, abdominal distension, and a disordered bowel habit) and exclusion of organic disease. Criteria outlined by Manning and colleagues ${ }^{54}$ help to diagnose the condition more positively, thus allowing studies on the disorder to be more comparable. The more recently defined "Rome criteria" 35 provide an international consensus on diagnosis and adequate entry criteria for a clinical trial in IBS. Of the 47 trials identified, six used Manning criteria, ${ }^{54}$ six used Rome criteria, ${ }^{55}$ and the remaining 35 trials used either symptoms of IBS, or defined one, two, or three symptoms of IBS as entry criteria. 
Classification into diarrhoea predominant and constipation predominant categories appears to reflect physiological differences between each type. ${ }^{56}$ For studies on prokinetic drugs, ${ }^{37-39}$ entry criteria required patients to have constipation predominant symptoms. However, of seven antidiarrhoeal trials only one used the presence of diarrhoea predominant IBS as an entry criterion.

It is recommended that patients meet clear standardised entry criteria to be included in trials. Talley and colleagues $^{57}$ recommend the use of the Rome criteria. The authors also recommend that limiting trials to defined subgroups of patients should be considered to enhance homogeneity of the study population.

\section{STUDY DESIGN}

Considerations that are especially relevant to the design of controlled treatment trials for IBS are the use of placebo control, study duration, baseline comparisons, maintaining blindedness, and the appropriateness of the commonly used crossover design. There were a number of common problems with the studies identified. A major problem with designing RCTs for the treatment of IBS is the placebo response, which is extremely variable and high, most frequently between $40 \%$ and $70 \% .^{58}$ This was a particular problem in three studies reported in table $1 . .^{711}$ Differences of this magnitude reflect not only the nature of the patients enrolled in a trial but the methods used to determine treatment response. It is impossible to be certain that even marked improvements are due to the intrinsic properties of the treatment being tested unless there is a placebo control group. Therefore, it is recommended that all IBS trials be placebo controlled. ${ }^{57} 58$

All of the trials included clearly mentioned the number of patients given either treatment or placebo. One study provided incomplete information concerning the number of dropouts ${ }^{40}$ and one study failed to mention the number of dropouts. ${ }^{29}$

RANDOMISATION

All of the 45 studies were considered to be RCTs yet only seven mentioned the method of randomisation. ${ }^{1011} 1722273031$ The other 40 trials may have been appropriately randomised yet failed to describe the method of randomisation. It is considered important not only to describe the method of randomisation but also to provide information regarding the frequency of a variety of characteristics in the treatment and control groups to ensure adequate similarity between the two groups. ${ }^{57}$

\section{BLINDING}

Forty one of 47 RCTs were double blinded. None of the four studies ${ }^{26-29}$ on combinations of drugs with bulking agents or high fibre diet were blinded. This was expected as it would be difficult to achieve blinding in such studies. No blinding was possible in the study of Shaw and colleagues $^{24}$ in which peppermint oil treatment was compared with a stress management programme. Talley and colleagues ${ }^{57}$ recommend that all IBS trials are double blinded. Where this is not possible such as in non-drugs trials of treatments such as psychotherapy, it is essential that independent evaluators are used to rate the effectiveness of treatment.

\section{TREATMENT PERIOD (DURATION OF TRIALS)}

IBS is usually a chronic, sometimes lifelong, condition with unpredictable periods of exacerbation and remission. Thus clinical trials of only a few days or weeks are of limited relevance for establishing that a treatment is effective. As can be seen from table 1, the majority of IBS treatment trials were of insufficient duration to be clinically relevant. The studies that fulfilled the Jadad criteria ${ }^{1}$ reported treatment periods varying from one month ${ }^{22}$ to six months. ${ }^{27}$ In all 45 trials, the duration of the treatment period is clearly mentioned together with any washout period in the crossover trials. It is recommended that trials of IBS treatments be a minimum of 8-12 weeks' duration. ${ }^{57}$ Maxton and colleagues $^{59}$ suggest a total trial duration of approximately 12 weeks.

\section{OUTCOME MEASURES}

Because there are no objective markers in improvement of IBS, determination of efficacy in treatment trials is based on somewhat arbitrary rating scales. A change in abdominal pain, bowel habit, and overall well being are the main outcome measures used in IBS trials, with distension tending to be neglected, although patients often perceive it as severe. ${ }^{58}$ The studies reported here used a range of outcome measures, including nausea, vomiting, abdominal pain (frequency, severity, and duration), bowel habit (frequency, consistency of stools, and transit time), distension, and overall symptom scores, as assessed by the patient or physician. Specific measures were also used, appropriate to the therapeutic agent. For example, in a tricyclic antidepressant study, a standard measure of depression (Hamilton-D score) was used as it was anticipated that a significant proportion of enrolled patients would be depressed. ${ }^{30}$ Northcutt and colleagues ${ }^{60}$ used adequate pain relief as an outcome measure in their study of alosteron, a 5- $\mathrm{HT}_{3}$ receptor antagonist. In a review, Talley and colleagues ${ }^{57}$ strongly proposed the need to develop sensitive symptom outcome measures as a priority among their recommendations to optimise IBS trials. The authors recommended that symptom outcome measures should include multiple domains and that quality of life should be assessed in addition to gastrointestinal symptoms. They also suggest that global assessment scales are useful although further research is needed to determine the degree to which global well being and health or symptoms are correlated. If resources to expand the treatment of IBS are to be found, future studies will need to include generic quality of life measures to allow comparison with effects in completely different therapeutic areas.

REVIEWS OF IBS TREATMENTS

No Cochrane review of IBS treatments was identified in this review. However, other reviews have highlighted the flaws in IBS study design. For example, Pace and colleagues, ${ }^{61}$ in a review of fibre supplementation, found the studies to be flawed due to high placebo response, small sample size, short duration of treatment, inadequate dose or mode of fibre delivery, and ill defined inclusion criteria. The authors also found that in the five antidepressant studies reviewed, all had methodological and statistical problems.

A recent meta-analysis by Pittler and Ernst ${ }^{62}$ reported that the role of peppermint oil in the symptomatic treatment of IBS has not been established and carefully executed studies are needed to clarify the issue. In a review of anticholinergics, all eight studies were judged to be flawed and with conflicting results. ${ }^{61}$ A meta-analysis of 26 selected double blind, randomised trials was performed by Poynard and colleagues ${ }^{63}$ which included eight drugs: cimetropium bromide, dicyclomine hydrochloride, mebeverine, hyoscine butyl bromide, octylonium bromide, peppermint oil, pinaverium bromide, and trimebutine. Only five drugs (cimetropium bromide, mebeverine, octylonium bromide, pinaverium bromide, and trimebutine) have been shown to be clinically effective in patients with IBS without adverse reactions. 


\section{Conclusions}

IBS is a challenging disorder that affects many individuals, and its treatment is extremely complex. A variety of processes appear to be at work and IBS sufferers are not a homogeneous population. Therefore, not all treatments will be suitable for all IBS patients. Rather, certain interventions will be effective towards specific aspects of IBS.

The literature review of treatments for IBS identified few RCTs and a poor overall quality of research. The majority of published trials failed to meet even simple criteria for acceptability. Despite this, a variety of interventions have been shown to be clinically effective in the treatment of symptoms of IBS, although no drug is effective in treating all symptoms. A variety of outcome measures have been used, making it difficult to compare the results of trials.

Several new drugs are currently being developed which show promise in the treatment of IBS. ${ }^{64}$ It is essential that RCTs are conducted of consistently identified patients with clearly defined outcome measures. These outcome measures should not only deal with symptom relief but also improvement in quality of life and associated measures such as time off work.

R AKEHURST

E KALTENTHALER

School of Health and Related Research (ScHARR),

University of Sheffield, Regent Court, 30 Regent Street,

Sheffield S1 4DA, UK

Correspondence to: Professor Akehurst.r.l. akehurst@sheffield.ac.uk

The authors would like to acknowledge and thank Raksha Ramchand for the substantial contributions she has made to this paper.

1 Jadad AR, Moore RA, Caroll D, et al. Assessing the quality of reports of randomised clinical trials: is blinding necessary? Controlled Clin Trials 1996;17:1-12.

2 Thompson WG, Creed F, Drossman DA, et al. Functional bowel disease and functional abdominal pain. Gastroenterol Int 1992;5:75-91.

3 Camilleri M, Choi MG. Review article: irritable bowel syndrome. Aliment Pharmacol Ther 1997;11:3-15.

4 Malcolm A, Kellow JE. Irritable bowel syndrome: what it is and what to do about it. Modern Med 1998;15:74-86.

5 Farthing MJG. Irritable bowel, irritable body or irritable brain. BMf 1995; 310:171-5.

6 Akehurst RL. Burden of illness of irritable bowel syndrome. An interim report on behalf of Novartis Pharma AG, Basel, Switzerland. Sheffield: ScHARR, University of Sheffield, 1999 .

7 Cook IJ, Irvine EJ, Campbell D, et al. Effect of dietary fibre on symptoms of rectosigmoid motility in patients with irritable bowel syndrome. A controlrectosigmoid motility in patients with irritable bowel

8 Jalihal A, Kurian G. Ispaghula therapy in irritable bowel syndrome: improvement in overall well-being is related to reduction in bowel dissatisaction. F Gastroenterol Hepatol 1990;5:517-13.

9 Lucey MR, Clark ML, Lowndes J, et al. Is bran efficacious in irritable bowel syndrome? A double-blind placebo controlled crossover study. Gut 1987;28:221-5.

10 Prior A, Whorwell PJ. Double blind study of ispaghula in irritable bowel syndrome. Gut 1987;28:1510-13.

11 Snook J, Shepherd HA. Bran supplementation in the treatment of irritable bowel syndrome. Aliment Pharmacol Ther 1994;8:511-14.

12 Toskes PP, Connery KL, Ritchey TW. Calcium polycarbophil compared with placebo in irritable bowel syndrome. Aliment Pharmacol Ther 1993;7: $87-92$.

13 Tomas Ridocci M, Anon R, Minguez M, et al. The efficacy of plantago ovata as a regulator of intestinal transit. A double-blind study compared to placebo. Rev Esp Enferm Dig 1992;82:17-22.

14 Awad R, Dibildox M, Ortiz F. Irritable bowel syndrome using pinaverium bromide as a calcium blocker. A randomised double-blind placebo-
controlled trial. Acta Gastroenterol Latinoam 1995;25:137-44.

15 Baldi F, Longanesi A, Blasi A, et al. Octylonium bromide in the treatment of the irritable bowel syndrome: a clinical functional study. Hepatogastroenterology 1992;39:392-5.

16 Centonze V, Imbimbo BP, Campanozzi F, et al. Oral cimetropium bromide, a new muscarinic drug, for long-term treatment of irritable bowe syndrome. Am f Gastroenterol 1988;83:1262-6.

17 Dobrilla G, Imbimbo BP, Piazzi L, et al. Long term treatment of irritable bowel syndrome with cimetropium bromide: a double blind placebocontrolled trial. Gut 1990;31:355-8.

18 Lawson MJ, Knight RE, Tran K, et al. Failure of enteric-coated peppermint oil in the irritable bowel syndrome: A randomised, double-blind cross-over study. F Gastroenterol Hepatol 1988;3:235-8.

19 Lech AY, Olesen KM, Hey H, et al. Behandling af colon irritabile med pebermynteolie. Ugeskr Laeger 1988;150:2388-9.

$20 \mathrm{Liu}$ JH, Chen GH, Yeh HZ, et al. Enteric-coated peppermint-oil capsules in the treatment of irritable bowel syndrome: A prospective, randomised trial. f Gastroenterol 1997;32:765-8.
21 Mollica G, Manno G. Otilonium bromide-diazepam in the treatment of the irritable colon. A controlled study versus otilonium bromide. Clin Ther 1992;141:129-34

22 Passaretti S, Guslandi M, Imbimbo BP, et al. Effects of cimetropium bromide on gastrointestinal transit time in patients with irritable bowel syndrome. Aliment Pharmacol Ther 1989;3:267-76.

23 Schafer E, Ewe K. The treatment of irritable colon. Efficacy and tolerance of buscopan plus, buscopan, paracetamol and placebo in ambulatory patients with irritable bowel colon. Fortschr Med 1990;108:488-92.

24 Shaw G, Srivastava ED, Sadlier M, et al. Stress management for irritable bowel syndrome: a controlled trial. Digestion 1991;50:36-42.

25 Van Outryve M, Mayeur S, Meeus MA, et al. A double-blind crossover comparison study of the safety and efficacy of mebeverine and mebeverine sustained release in the treatment of irritable bowel syndrome. 7 Clin Pharm Ther 1995;20:277-82.

26 Chapman ND, Grillage MG, Mazumder R, et al. A comparison of mebeverine with high-fibre dietary advice and mebeverine plus ispaghula in the treatment of irritable bowel syndrome: an open prospectively randomised parallel group study. Br F Clin Pract 1990;44:461-6.

27 Misra SP, Thorat VK, Sachdev GK, et al. Long-term treatment of irritable bowel syndrome: results of a randomised controlled trial. $Q \mathcal{F} \mathrm{Med}$ 1989;73:931-9.

28 Nayak AK, Karnad DR, Abrahaam P, et al. Metronidazole relieves symptoms in irritable bowel syndrome: the confusion with so-called 'chronic amebiasis'. Ind 7 Gastroenterol 1997; 16:137-9.

29 Villagrasa M, Boix J, Humbert P, et al. Aleatory clinical study comparing otilonium bromide with a fibre-rich diet in the treatment of irritable bowel syndrome. Ital $\mathcal{F}$ Gastroenterol 1991;23:67-70.

30 Alevizos B, Christodoulou GN, Loannidis C, et al. The efficacy of amineptine in the treatment of depressive patients with irritable bowel syndrome. Clin Neuropharmacol Supplement 1989;2:S66-76.

31 Barbier JP, Dorf G, Gordin J, et al. Effect of a buzepide metiodidehaloperidol combination in treating functional intestinal disorders. Randomised double-blind controlled versus placebo study. Ann Gastroenterol Hepatol Paris 1989;3:123-8.

32 Greenbaum DS, Mayle JS, Vanegeren LE, et al. Effects of desipramine on irritable bowel syndrome compared with atropine and placebo. Dig Dis Sci 1987;32:257-66.

33 Tanum L, Malt UF. A new pharmacological treatment of functional gastrointestinal disorder. A double-blind placebo-controlled with mianserin. Scand 7 Gastroenterol 1996;31:318-25.

34 Goldberg PA, Kamm MA, Setti CP, et al. Modification of visceral sensitivity and pain in irritable bowel syndrome by 5-HT3 antagonism (ondansetron). Digestion 1996;57:478-93.

35 Maxton DG, Morris J, Whorwell PJ. Selective 5-hydroxytryptamine antagonism: a role in irritable bowel syndrome and functional dyspepsia? Aliment Pharmacol Ther 1996;10:595-9.

36 Steadman CJ, Talley NJ, Phillips SF, et al. Selective 5-hydroxytryptamine type 3 receptor antagonism with ondansetron as treatment for diarrhoea67:732-8.

37 Farup PG, Hovdenak N, Wettterhus S, et al. The symptomatic effect of cisapride in patients with irritable bowel syndrome and constipation. Scand $\mathcal{F}$ Gastroenterol 1998;33:128-31.

38 Schutze K, Brandstatter G, Dragoisics B, et al. Double-blind study of the effect of cisapride on constipation and abdominal discomfort as components of the irritable bowel syndrome. Aliment Pharmacol Ther 1997; 11:387-94.

39 Van Outryve M, Milo R, Touissaint J, et al. 'Prokinetic' treatment of constipation-predominant irritable bowel syndrome: A placebo-controlled study of cisapride. F Clin Gastroenterol 1991;13:49-57.

40 Efskind PS, Bernklev T, Vatn MH. A double-blind placebo-controlled trial with loperamide in irritable bowel syndrome. Scand 7 Gastroenterol 1996;31:463-8.

41 Halpern GM, Prindiville T, Blankenburg M, et al. Treatment of irritable bowel syndrome with Lacteol Fort: a randomised, double-blind, cross-over trial. Am 7 Gastroenterol 1996;91:1579-85.

42 Hovdenak N. Loperamide treatment of the irritable bowel syndrome. Scand 7 Gastroenterol Suppl 1987;130:81-4.

43 Lavo B, Stenstam M, Nielsen AL. Loperamide in treatment of irritable bowel syndrome: a double-blind placebo controlled study. Scand f Gastroenterol Suppl 1987;130:77-80.

44 Lunardi C, Bambara LM, Biasi D, et al. Double-blind cross-over trial of oral sodium cromoglycate in patients with irritable bowel syndrome due to food intolerance. Clin Exp Allergy 1991;21:569-72.

45 Prior A, Wilson KM, Whorwell PJ. Double-blind study of an alpha 2 agonist in the treatment of irritable bowel syndrome. Aliment Pharmacol Ther 1988; 2:535-9

46 Rodnitz-Magallan A, Valadez-Velazquez T, Llorens-Torres F, et al. Treatment of irritable colon with lidamidine and support psychotherapy. Rev Gastroenterol Mex 1997;62:7-13.

47 Cann PA, Rovati LC, Smart HL, et al. Loxiglumide, a CCK-A antagonist, in irritable bowel syndrome. A pilot multicenter clinical study. Ann N Y Acad Sci 1994;713:449-50.

48 Dapoigny M, Abitboll JL, Fraitag B. Efficacy of peripheral kappa agonist fedotozine versus placebo in treatment of irritable bowel syndrome. A multicenter-dose response study. Dig Dis Sci 1995;40:2244-8.

49 Gade J, Thorn P. Paraghurt for patients with irritable bowel syndrome. A controlled clinical investigation from general practice. Scand $\mathcal{F}$ Prim Health Care 1989;7:23-6.

50 Mathias JR, Clench MF, Reeves Darby VG, et al. Effect of leuprolide acetate in patients with moderate to severe functional bowel disease. Double-blind placebo-controlled study. Dig Dis Sci 1994;39:1155-62.

51 Mathias JR, Clench MH, Roberts $\mathrm{PH}$, et al. Effect of leuprolide acetate in patients with functional bowel disease. Long-term follow-up after doubleblind placebo-controlled study. Dig Dis Sci 1994;39:1163-70.

52 Moher D, Jadad AR, Nicol G, et al. Assessing the quality of randomized controlled trials: an annotated bibliography of scales and checklists. Control Clin Trials 1995;16:62-73.

53 Clouse RE. Antidepressants for functional intestinal syndromes. Dig Dis Sci 1994;39:2352-63.

54 Manning AP, Thompson WG, Heaton KW, et al. Towards positive diagnosis of the irritable bowel. BMF 1978;2:653-4. 
55 Thompson WG, Dotevall G, Drossman D, et al. Irritable bowel syndrome: guidelines for the diagnosis. Report of the Rome Working Team. Gastroenterol Int 1989;2:92-5.

56 Prior A, Maxton DG, Whorwell PJ. Anorectal manometry in irritable bowel syndrome: differences between diarrhoea and constipation predominant subjects. Gut 1990;31:452-62.

57 Talley NJ, Nyren O, Drossman DA, et al. The irritable bowel syndrome: toward optimal design of controlled treatment trials. Gastroenterol Int 1993 6:189-211.

58 Maxton DG, Morris JA, Whorwell PJ. Ranking of symptoms by patients with the irritable bowel syndrome. BMF 1989;299:1138.

59 Maxton DG, Morris J, Whorwell PJ. Improving clinical trials in irritable bowel syndrome: some practical aspects. Eur f Gastroenterol Hepatol 1992;4:337-41.
60 Northcutt AR, Camilleri M, Mayer EA, et al. Alosteron, a 5HT, receptor antagonist, is effective in the treatment of female irritable bowel syndrome. Gastroenterology 1998;114:A812.

61 Pace F, Coremans G, Dapoigny $\mathrm{M}$, et al. Therapy of irritable bowel syndrome. An overview. Digestion 1995;56:433-42.

62 Pittler MH, Ernst E. Peppermint oil for irritable bowel syndrome: A critical review and metaanalysis. Am 7 Gastroenterol 1998;93:1131-5.

63 Poynard T, Naveau S, Mory B, et al. Meta-analysis of smooth muscle relaxants in the treatment of irritable bowel syndrome. Alim Pharmacol Ther 1994;8:499-510.

64 Morgan Stanley Dean Witter. An investor's primer to irritable bowel syndrome (IBS). European Investment Research, 2 June 1999. 